\title{
Crosslinking of Chrysophyllum albidum gum with calcium chloride to enhance its physicochemical, compressional and tableting properties
}

\author{
Lateef G. BAKRE * D, Keji E. AKINSANYA
}

Department of Pharmaceutics and Pharmaceutical Technology, Faculty of Pharmacy, Olabisi Onabanjo University, Ago Iwoye, Nigeria.

* Corresponding Author. E-mail: lateef.bakre@oouagoiwoye.edu.ng; lateefbakr@yahoo.com (L.G.B.); Tel. +2348033700102 .

Received: 08 January 2019 / Revised: 26 January 2019 / Accepted: 29 January 2019

\begin{abstract}
This work aims to evaluate the effect of cross-linking on the physicochemical and compressional characteristics of Chrysophyllum albidum gum and the mechanical and release properties of its metformin tablet formulation. The physicochemical properties of the native (NCAG) and cross-linked Chrysophyllum albidum gum (CCAG) were evaluated using established methods while the compressional characteristics were determined using density measurements and indices of plasticity derived from Heckel and Kawakita equations. The mechanical properties were evaluated and the time taken for $50 \%\left(\mathrm{~T}_{50}\right)$ and $90 \%\left(\mathrm{~T}_{90}\right)$ drug dissolution were determined. CCAG had better flow, lower bulk density and a swelling capacity almost twice as that of the NCAG. The DSC results reveal no potential interaction between the gum and the cross linking agent. The compressional properties show that CCAG had higher $P_{y}$ but lower $P_{k}$ values than NCAG. This suggests that CCAG induced slower onset of plastic deformation than NCAG but its overall amount of plastic deformation was higher. Metformin tablets containing CCAG gum were softer and more friable. All the tablets formulated with both NCAG and CCAG passed the disintegration test. Generally, tablets formulated with CCAG had shorter disintegration time. The $\mathrm{T}_{50}$ and $\mathrm{T}_{90}$ values show that the formulation containing $7.5 \% \mathrm{w} / \mathrm{w}$ cross-linked Chrysophyllum albidum gum had the least dissolution time. The result suggests that cross-linking of the gum resulted in improved physicochemical and compressional properties and a better release profile of its metformin tablet formulation. These improved properties could be explored in tablet formulation and production.
\end{abstract}

KEYWORDS: Chrysophyllum albidum gum; cross-linking; calcium chloride; physicochemical characteristics; compressional characteristics; release properties.

\section{INTRODUCTION}

The development of new excipients from natural sources with improved functionalities has received attention in pharmaceutical research because of the growing need to meet the demands of newer drug delivery systems. Natural polymers have been modified to produce new sets of functionalities using a wide variety of methods such as co-processing, pregelatinization, annealation, oxidation, acetylation, enzyme hydrolysis, acid hydrolysis and crosslinking [1-4]. Cross linking of polymers affects the molecular structure and consequently alters its physical characteristics. It involves augmenting bonds with chemical bridges between the molecules or polymer chains. Depending on the polymer nature, different methods may be used to achieve cross linking namely covalent bonding between polymeric chain via irradiation, polymerization of monomers by condensation, or by adding different crosslinking agents in addition to heating (ionic gelation). In all these cases, the chemical structure of the polymer is altered through the crosslinking process. Ionic gelation technique involves the interaction of an oppositely charge ion with the polymer chain to initiate the formation of a strongly bonded molecular chain network [5]. Cross-linked polymer networks have been widely used in drug delivery as swellable devices or as disintegrants due to their ability to absorb water and swell considerably [6].

Polysaccharides obtained from natural sources such as gums, starches and celluloses and their derivatives have been widely used in drug formulations and in controlled drug delivery system [7]. They can

How to cite this article: Bakre LG, Akinsaya KE. Crosslinking of Chrysophyllum albidum gum with calcium chloride to enhance its physicochemical, compressional and tableting properties. J Res Pharm. 2019; 23(3): 415-425. 
be extracted from plants at relatively low cost and can be chemically modified to suit specific needs. Gums have been employed in pharmaceutical formulations for a variety of functions such as disintegrants, binders, emulsifiers, drug release modifiers and thickeners where they are used either in their natural forms or as derivatives after some modifications [8]. These modifications result in some structural changes and are tailored to meet the needs of newer delivery systems or suit particular interests in pharmaceutical raw material development. Cross-linking as a method of gum modification comprises re-enforcing bonds with chemical bridges between the polymer chains. Consequently, the cross-linked gum may have more resistance to high shear, high temperature and have improved textural properties and viscosity than the natural gum. Chrysophyllum albidum commonly called white star apple belongs to the family of Sapotaceae and it is common in the tropics and other parts of the world [9]. The fruit is ovoid in shape, pointed at the apex and the peel is orange to golden yellow when ripe. The fleshy pulp has around three to five hard, shiny, dark brown and bony seeds arranged in a star- shaped pattern. It is seasonal (usually from December to March) and the fleshy fruit pulp is suitable for jams. Chrysophyllum albidum gum extracted from the fruit had been characterized, used as binder and employed as polymer in sustained release formulation [10-13]. However, it appears little or no work has been done on studying the effect of cross-linking on the properties of the gum and its tablet formulation. This study is therefore designed to cross-link Chrysophyllum albidum gum with calcium chloride using the ionic gelation method to enhance its physicochemical, compressional and tableting properties. Calcium chloride was selected as the cross- linking agent because it is non - toxic, cheap and environmental friendly.

\section{RESULTS AND DISCUSSION}

\subsection{FTIR characterization and thermal properties of Chrysophyllum albidum gum}

The spectra of native Chrysophyllum albidum gum (NCAG) showed the presence of characteristic broad band at $3291 \mathrm{~cm}^{-1}$ which is attributable to hydrogen bonded -OH (Figure 1a).
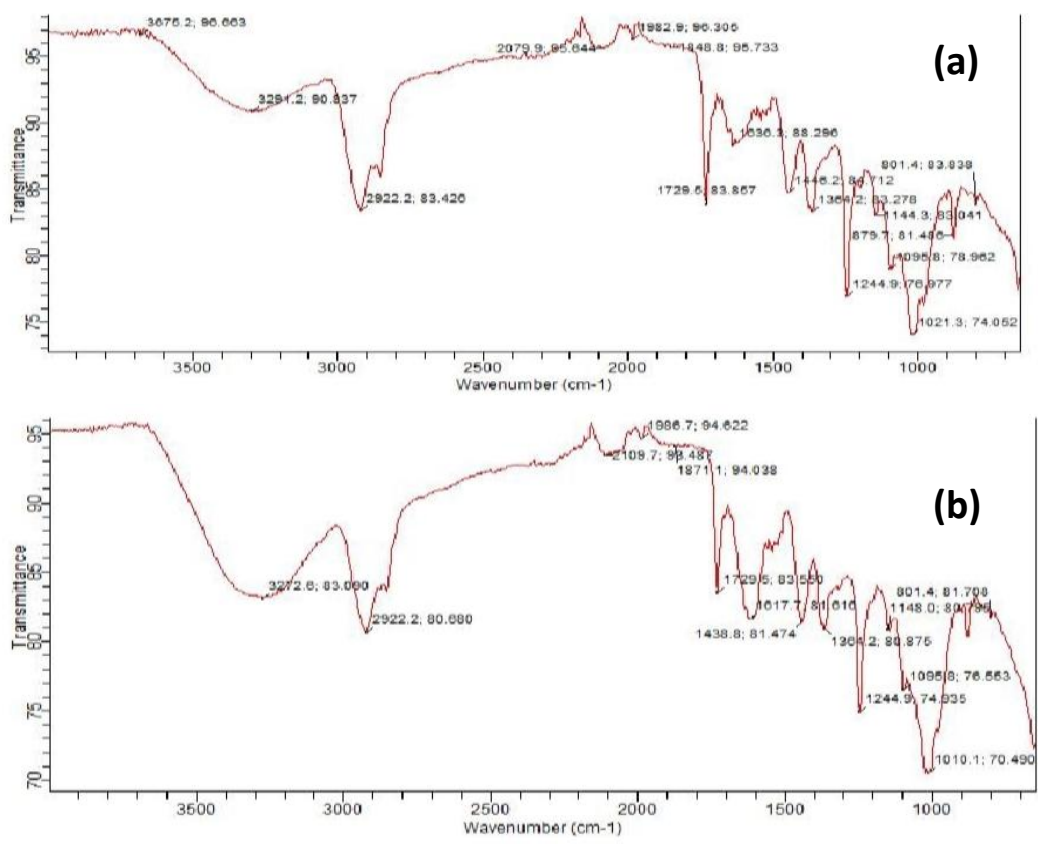

Figure 1. (a) FTIR spectrum of native Chrysophyllum albidum gum; (b) FTIR spectrum of cross-linked Chrysophyllum albidum gum.

The stretching peak at $2922 \mathrm{~cm}^{-1}$ can be assigned to $-\mathrm{CH}$ while the strong sharp peak at $1729 \mathrm{~cm}^{-1}$ is due to carbonyl $\mathrm{C}=\mathrm{O}$ stretch. The FTIR spectra of cross-linked Chrysophyllum albidum gum (CCAG) showed that the vibration of the functional groups are affected by the cross linking reaction. Some peaks disappeared or becomes stronger as a result of the superimposition of peaks of the functional groups of calcium chloride and Chrysophyllum albidum gum. It is noteworthy that the $\mathrm{C}=\mathrm{O}$ carbonyl stretch at $1729 \mathrm{~cm}^{-1}$ was still retained in CCAG suggesting that Chrysophyllum albidum gum did not interact with calcium chloride during the 
crosslinking process. There was a slight shift in the characteristic peak at $3291 \mathrm{~cm}^{-1}$ in NCAG to $3272 \mathrm{~cm}^{-1}$ in CCAG. Although, the shift is small, it could be due to a decrease in the degree of hydrogen bonding in the crosslinked gum. This suggests a possible reaction of $\mathrm{Ca}{ }^{2+}$ with $-\mathrm{OH}$ groups resulting in the formation of polyamine- cationic complexes. A similar behavior has been reported when alginate was crosslinked with calcium chloride solution [14]. The absorption band at $1617 \mathrm{~cm}^{-1} \mathrm{can}$ be attributed to the stretching vibration of $\mathrm{Ca}=\mathrm{O}$ and the peaks at $1010 \mathrm{~cm}^{-1}$ were that of Ca-O-C. Figure 2 represents the DSC curves for the powder samples which reveal an endothermic peak at $110^{\circ} \mathrm{C}$ in NCAG and CCAG. The decomposition temperature of NCAG and CCAG were $258^{\circ} \mathrm{C}$ and $240{ }^{\circ} \mathrm{C}$ respectively. This suggests that there was no significant changes in the structural framework of the gum and the cross linking process simply joined the polymer strands together. The DSC results reveal no potential interaction between the gum and the cross linking agent.

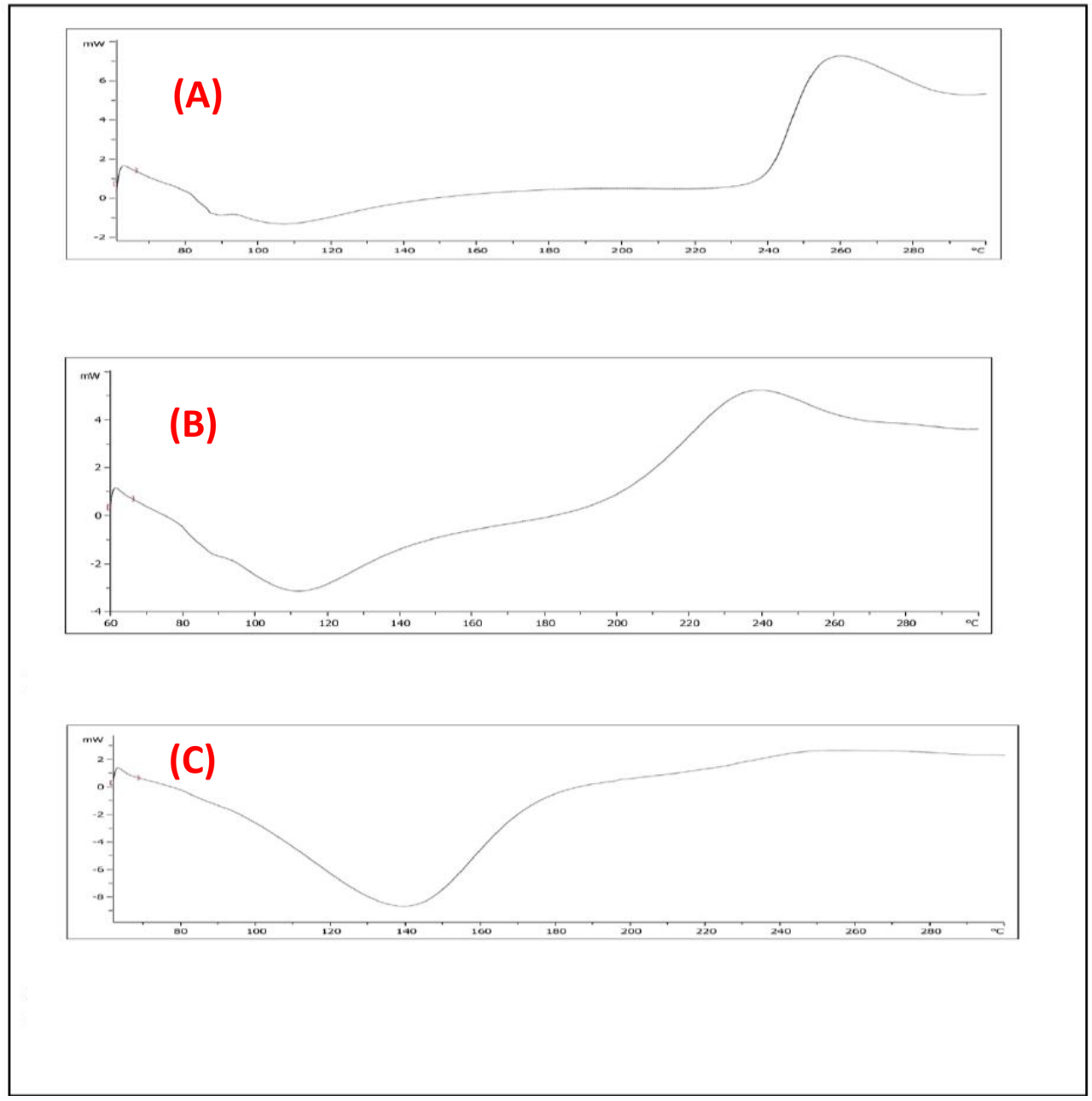

Figure 2. (a) DSC thermogram of native Chrysophyllum albidum gum; (b) DSC thermogram of cross-linked Chrysophyllum albidum gum; (c) DSC thermogram of 50:50 binary mixture of Chrysophyllum albidum gum and calcium chloride.

\subsection{Physicochemical and compressional properties of Chrysophyllum albidum gum}

Information on the physicochemical properties of a pharmaceutical raw material such as the flow properties, densities and swelling capacity will help to predict the properties it will exhibit when used as an excipient in the manufacture of tablets. The tapped and bulk densities are a reflection of the flow properties, arrangement and packing powders of the particles and therefore the compressibility of the powder [15]. A high value of bulk density is always an advantage in tableting because of a reduction in the die fill volume. 


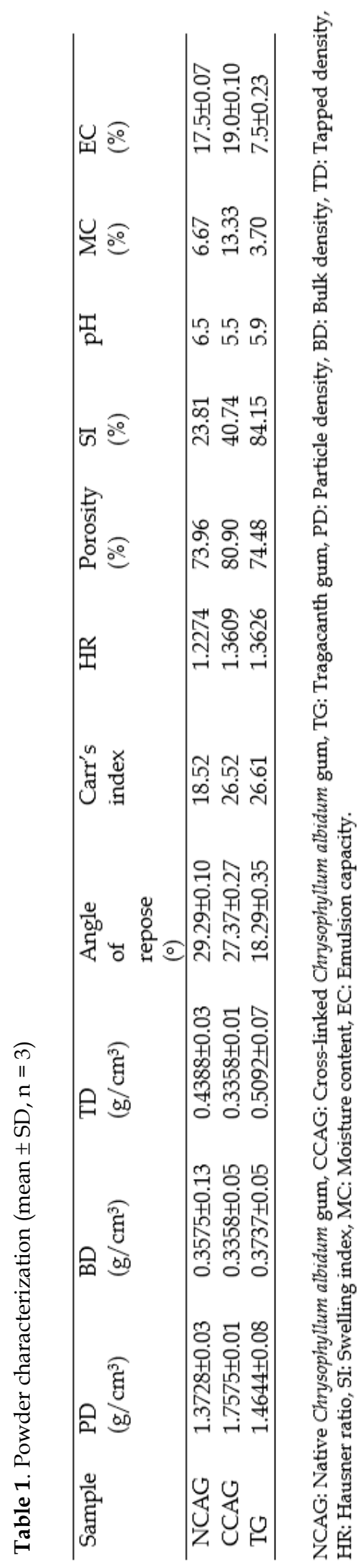

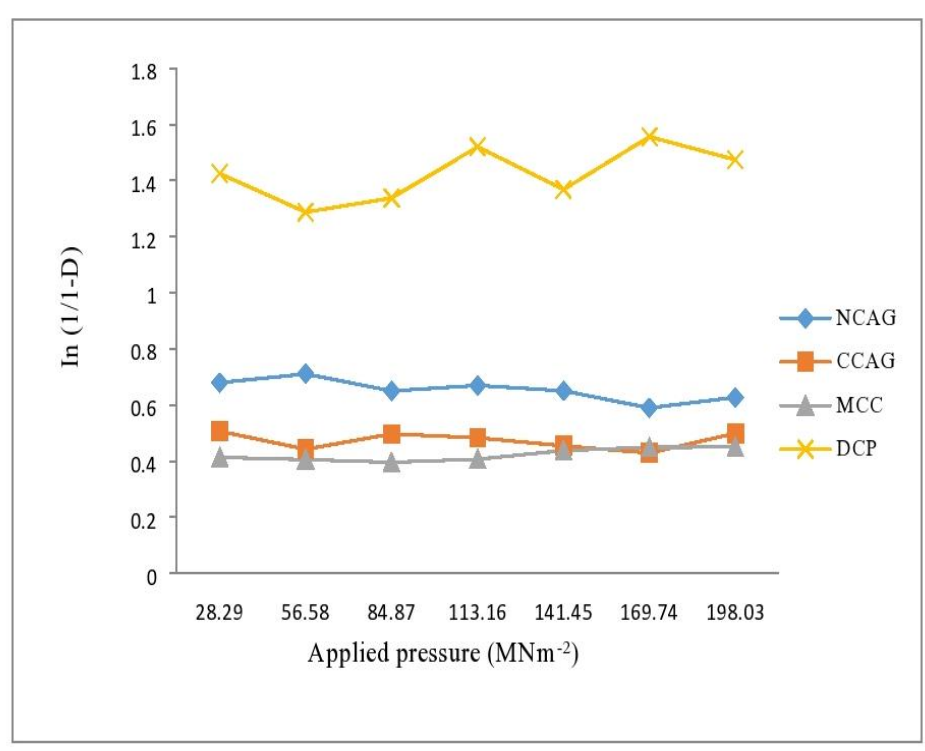

Figure 3. Representative Heckel plot.

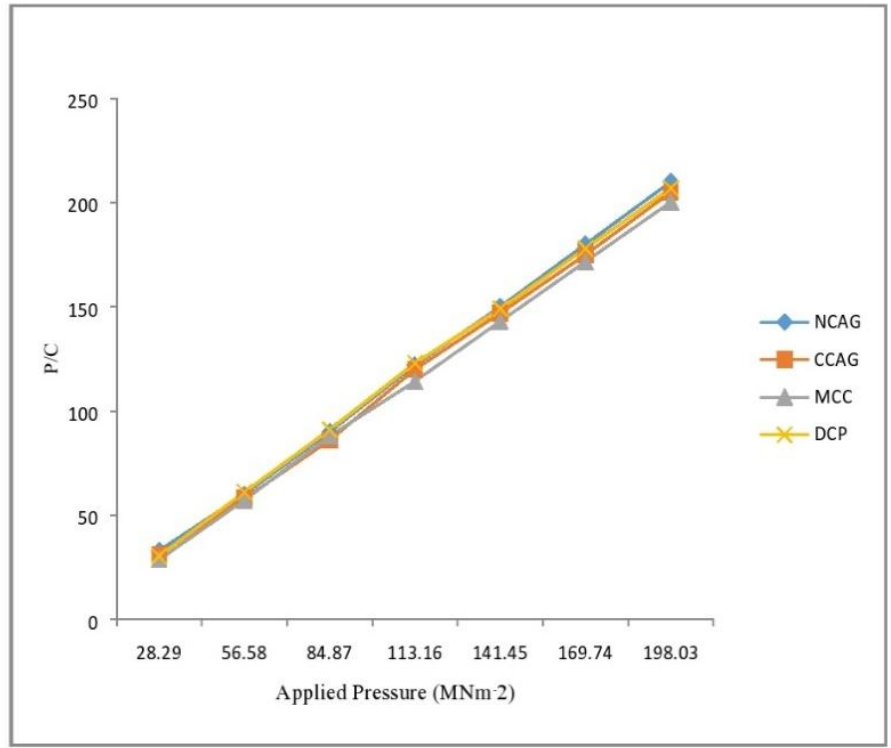

Figure 4. Representative Kawakita plot. 
The density values are presented in Table 1 . The particle and the tapped densities of CCAG are higher than that of NCAG but CCAG has a lower bulk density. The angle of repose, Hausner ratio and Carr's index are indirect measurements of powder flowability [16]. The rank order for the angle of repose as obtained is: Tragacanth gum < CCAG < NCAG. The higher the angle of repose, the more cohesive the powder and the poorer the flow rate. The cross-linking of the gum therefore resulted in better flow properties. The physiological activity and stability of most preparations depend on its $\mathrm{pH}$ which suggests that the $\mathrm{pH}$ of an excipient plays a significant role in the determining its suitability in formulations [17]. The $\mathrm{pH}$ of CCAG was 5.5 which is slightly acidic and might need to be buffered if it is to be employed in oral and buccal delivery system. The swelling capacity has significant influence on disintegration and has been used extensively to predict excipient's disintegration ability [18]. The swelling capacity of the CCAG was almost twice that of the NCAG. In addition, CCAG had the highest porosity and would therefore enhance water uptake by capillary action. This suggests that CCAG will likely be a better disintegrant with capillary action and swelling as possible mechanisms of disintegration. CCAG possesses high moisture content, therefore it should be stored in air-tight containers to prevent absorption of moisture and microbial attack. The cross-linking of gum slightly improved the foaming capacity. The Heckel and Kawakita plots are presented in Figures 3 and 4 respectively. The plots of both NCAG and CCAG exhibited a Type $C$ behavior having an initial steep linear region which flattens out as the applied pressure is increased. This is as a result of the absence of a rearrangement phase. The mean yield pressure, $\mathrm{P}_{\mathrm{y}}$ depicts the ability of a material to undergo fragmentation or deform plastically. CCAG has a higher value than NCAG. $P_{k}$ represents the pressure needed to reduce the volume of the powder bed by $50 \%$ and generally, lower values indicate soft and plastically deforming material. Microcrystalline cellulose (MCC) and dicalcium phosphate dihydrate (DCP) used in this study are model examples of plastically deforming and brittle materials respectively.

Table 2. Parameters derived from Heckel and Kawakita plots.

\begin{tabular}{lllllllll}
\hline & \multicolumn{3}{c}{ Heckel Parameters } & \multicolumn{5}{c}{ Kawakita Parameters } \\
\cline { 2 - 10 } Sample & $\mathrm{D}_{\mathrm{o}}$ & $\mathrm{P}_{\mathrm{y}}$ & $\mathrm{D}_{\mathrm{A}}$ & $\mathrm{D}_{\mathrm{B}}$ & $\mathrm{a}$ & $\mathrm{D}_{\mathrm{I}}$ & $\mathrm{b}$ & $\mathrm{P}_{\mathrm{K}}$ \\
\hline NCAG & 0.2604 & 70.42 & 0.5087 & 0.2483 & 0.0345 & 0.9655 & 91,73 & 0.0109 \\
CCAG & 0.1911 & 303.03 & 0.3850 & 0.1939 & 0.0346 & 0.9654 & 231.40 & 0.0043 \\
MCC & 0.0900 & 116.28 & 0.3217 & 0.2317 & 0.0350 & 0.9651 & 902.6 & 0.0011 \\
DCP & 0.3086 & 39.06 & 0.7333 & 0.4247 & 0.0342 & 0.9658 & 89.32 & 0.0112 \\
\hline
\end{tabular}

MCC: Microcrystalline cellulose; DCP: Dicalcium phosphate dihydrate.

Table 3. Mechanical properties of metformin tablet formulations

\begin{tabular}{llll}
\hline $\begin{array}{l}\text { Formulation } \\
\text { Code }\end{array}$ & $\begin{array}{l}\text { Crushing } \\
\text { Strength } \\
\left(\mathrm{Kg} / \mathrm{cm}^{3}\right)\end{array}$ & Friability (\%) & CSFR \\
\hline A & $3.31 \pm 0.24$ & $4.76 \pm 0.02$ & 0.36 \\
B & $3.50 \pm 0.00$ & $7.89 \pm 0.01$ & 0.44 \\
C & $3.20 \pm 0.24$ & $6.11 \pm 0.02$ & 0.52 \\
D & $2.72 \pm 0.23$ & $4.52 \pm 0.05$ & 0.60 \\
E & $4.51 \pm 0.41$ & $2.19 \pm 0.03$ & 2.05 \\
F & $3.82 \pm 0.23$ & $2.15 \pm 0.02$ & 1.77 \\
G & $3.01 \pm 0.00$ & $1.43 \pm 0.02$ & 2.10 \\
\hline
\end{tabular}

Table 2 shows that the rank order of $P_{k}$ values is: DCP> NCAG> CCAG> MCC. Cross-linking resulted in lower $P_{k}$ value which suggest that the cross-linked gum are softer and exhibited a higher overall amount of plastic deformation than the native gum. NCAG had a higher $D_{B}$ value than CCAG and therefore underwent greater phase of rearrangement in early stages of compression. 


\subsection{Mechanical and release properties of metformin tablets}

Table 3 presents the mechanical properties of metformin tablets. Generally, tablets containing the CCAG were softer and more friable than formulations containing NCAG. The crushing strength friability ratio (CSFR) evaluates the strength and the weakness of tablets and can therefore be used in assessing the mechanical strength of tablets. Higher CSFR values indicate stronger tablets. Formulations containing NCAG were stronger hence cross-linking of the gum reduced the strength of the tablets.

Table 4. Release parameters of metformin tablets.

\begin{tabular}{llll}
\hline $\begin{array}{l}\text { Formulation } \\
\text { Code }\end{array}$ & $\begin{array}{l}\text { Disintegration } \\
\text { time }(\mathrm{min})\end{array}$ & $\begin{array}{l}\mathrm{T}_{50} \\
(\mathrm{~min})\end{array}$ & $\begin{array}{l}\mathrm{T}_{90} \\
(\mathrm{~min})\end{array}$ \\
\hline A & 1.8 & 3.2 & 6.5 \\
$\mathrm{~B}$ & 3.2 & 3.3 & 9.7 \\
$\mathrm{C}$ & 3.0 & 2.3 & 7.3 \\
$\mathrm{D}$ & 2.3 & 1.1 & 5.7 \\
E & 3.0 & 1.3 & 8.3 \\
F & 3.3 & 2.9 & 6.5 \\
G & 3.1 & 3.4 & 7.1 \\
\hline
\end{tabular}

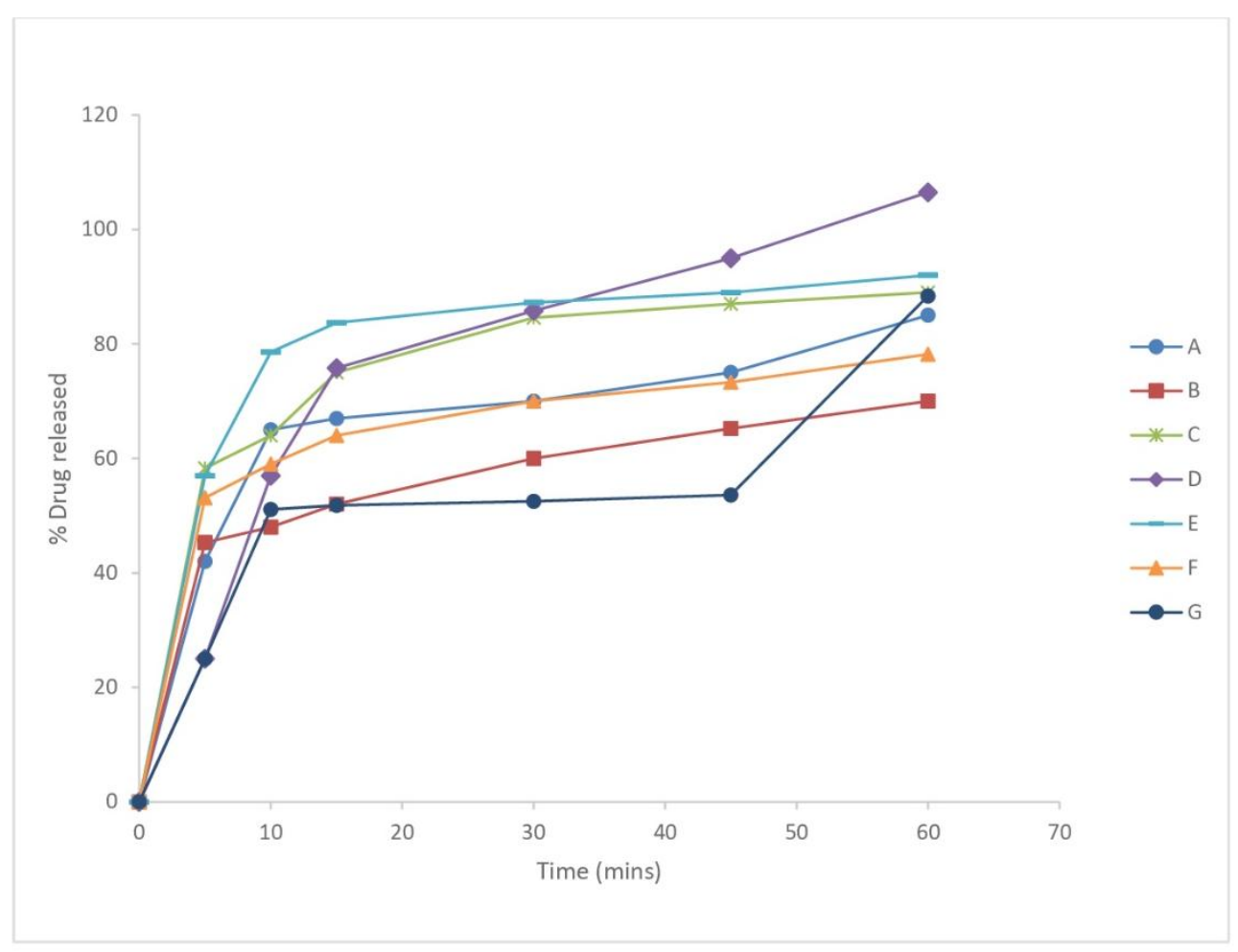

Figure 5. Representative plot of dissolution profile of metformin tablet formulations.

Table 4 shows that all the tablets formulated with CCAG and NCAG passed the disintegration test. The formulation containing $7.5 \%$ CCAG had the least disintegration time. As the concentration of the CCAG in the formulation increases, the disintegration time decreases. The result of the disintegration time correlates with the porosity and swelling capacity i.e CCAG which had better swelling capacity produced tablet which disintegrated faster than the tablets containing NCAG. The dissolution profiles of metformin tablet formulations are presented in Figure 5. The $T_{50}$ and $T_{90}$ values show that the formulation containing $7.5 \%$ 
CCAG had the least dissolution time. It was also observed that as the concentration of CCAG increased, the rate of dissolution of the tablet formulation became faster.

\section{CONCLUSION}

Cross-linking of Chrysophyllum albidum gum resulted in better flow properties, porosity and swelling capacity. However, the moisture content was higher and hence CCAG should be stored in air-tight containers. Metformin tablets containing CCAG were softer and more friable. Therefore, cross-linking produced tablets of lower mechanical strength. The compressional properties show that CCAG had higher $\mathrm{P}_{\mathrm{y}}$ but lower $\mathrm{P}_{\mathrm{k}}$ values than NCAG. This suggests that CCAG induced slower onset of plastic deformation than NCAG but its overall amount of plastic deformation was higher. All the tablets formulated with both NCAG and CCAG passed the disintegration test. Generally, tablets formulated with CCAG had shorter disintegration time. The disintegration ability of CCAG is concentration dependent. The formulation containing $7.5 \%$ CCAG had the fastest rate of dissolution.

\section{MATERIALS AND METHODS}

\subsection{Materials}

The materials used were Chrysophyllum albidum gum obtained from Chrysophyllum albidum fruit, metformin powder (Lifeline Pharmaceuticals, Mumbai), magnesium stearate and microcrystalline cellulose (BDH chemicals, U.K), di-calcium phosphate dihydrate, hydroxypropylmethyl cellulose and lactose powder (DMV, Veghel, Netherlands), calcium chloride (Tianjii Kermel Chemicals, China). All the reagents were of analytical grade and used without further purification.

\subsection{Extraction of Chrysophyllum albidum gum}

Chrysophyllum albidum fruits (without the seeds) were dried in the sun for three weeks. The dried clean fruits were soaked in distilled water for 10 hours and stirred periodically. The resulting mucilage was extracted exhaustively using $96 \%$ ethanol and then filtered with a white muslin cloth. The extracted gum was washed with $96 \%$ ethanol, air-dried and stored in a desiccator for further use.

\subsection{Preparation of cross-linked Chrysophyllum albidum gum}

The ionic gelation method reported by Mbah et.al [19] was used with slight modification. A $50 \mathrm{~g}$ quantity of Chrysophyllum albidum gum was weighed and dispersed in $1000 \mathrm{~mL}$ of distilled water and shaken for 24 hours. One litre of $1.0 \mathrm{M}$ calcium chloride solution was added to the solution, shaken for another six hours and allowed to stand for eight hours. The hydrated gum was then filtered using a clean white muslin cloth and washed serially with $99 \%$ alcohol and then air-dried. The material was then powdered and kept in a desiccator for further use.

\subsection{Powder characterization}

\subsubsection{Fourier transmission infrared spectra (FT-IR) spectroscopy}

The samples were dried and kept in a desiccator before the FTIR analysis. Spectra were obtained by using potassium bromide discs obtained from a mixture of the starch and dry potassium bromide on a FTIR spectrophotometer (BX 273, Perkin-Elmer, USA).

\subsubsection{Differential scanning calorimetry}

Differential scanning calorimetric (DSC) thermograms of the sample were determined on a Mettler instrument (DSC1, Toledo, USA). A 4-10 mg weight of sample were compressed into pellets in an aluminium pan and heated from 30 to $430{ }^{\circ} \mathrm{C}$ at a rate of $20^{\circ} \mathrm{C} / \mathrm{min}$ under inert nitrogen atmosphere with a flow rate of 20 mLmin-1. The reference used was an empty aluminum pan.

\subsubsection{Determination of $\mathrm{pH}$}

The $\mathrm{pH}$ of $1 \%$ dispersions of the gums was measured using a $\mathrm{pH}$ meter. Determinations were made in triplicates. 


\subsubsection{Density measurements}

The true density of the samples was determined using the fluid displacement method [11]. The bulk density of each sample was obtained by pouring $10 \mathrm{~g}$ of the gum at angle of $45^{\circ}$ into a $50 \mathrm{ml}$ measuring cylinder and the volume occupied was recorded. The bulk density was calculated from the ratio of the weight to the volume occupied. The procedure was repeated thrice and the mean calculated. The tapped density was obtained by subjecting $10 \mathrm{~g}$ of powder sample in a $50 \mathrm{ml}$ measuring cylinder to 100 taps at a standardized rate of 38 taps per minute [20]. The final tapped volume was obtained when the difference between 200 times taps is less than $2 \%$ [21]

The volume was noted and the tapped density was calculated from the ratio of the weight to the volume occupied. Determinations were made in triplicate. The porosity e, was derived from the true and tapped densities data using Equation 1:

$$
e=100\left(1-\frac{\text { Bulk density }}{\text { true density }}\right)
$$

\subsubsection{Determination of flow properties}

A $10 \mathrm{~g}$ quantity of powder sample was weighed and carefully poured through a glass funnel clamped $10 \mathrm{~cm}$ above a flat surface to form a conical heap. The height and the radius of the powder heap were measured. The angle of repose was obtained from the tangent of the ratio of the height to the radius of the cone. The Hausner ratio was obtained from the ratio of the tapped and bulk density while the Carr's index were calculated using Equations 2

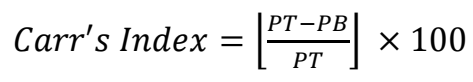

Where PT and PB are tapped and bulk densities respectively

\subsubsection{Determination of moisture content and foaming capacity}

The moisture content was determined by gravimetric method [11]. To determine the foaming capacity, $1 \mathrm{~g}$ of sample was weighed into $20 \mathrm{ml}$ distilled water and shaken for 30 minutes. This was allowed to stand for another 30 minutes and the volume of the foam was noted. The foaming capacity, FC was calculated using the equation below:

$$
F C=\frac{\text { Vol.of mix.after homogenization-vol.before homogenization }}{\text { volume before homogenization }} \times 100
$$

\subsubsection{Determination of emulsion capacity (\%)}

The method of Mbah et.al [19] was used with slight modification. Twenty (20) ml of olive oil was measured into a $50 \mathrm{ml}$ measuring cylinder. One gram of the gum was thoroughly dispersed in it, shaken and allowed to stand for 30 minutes. The volume of oil clearly above the sedimented gum was noted. The emulsion capacity was calculated using the Equation 4:

$$
\text { Emulsion capacity }=\frac{20 \mathrm{ml} \text {-vol of oil on top of sedimented gum }}{\text { weight of sample }} \times 100
$$

\subsubsection{Determination of Swelling Index}

A $10 \mathrm{~g}$ quantity of sample was weighed into a $100 \mathrm{ml}$ graduated cylinder and the volume occupied was noted $\left(\mathrm{V}_{0}\right)$. Distilled water $(30 \mathrm{mls})$ was added, the mixture shaken and allowed to stand for 24 hours. The final volume $(\mathrm{V})$ was recorded. The swelling index or capacity was obtained from percentage of the ratio of $\mathrm{V}$ to $\mathrm{V}_{0}$. Determinations was made in triplicate.

\subsection{Preparation of Chrysophyllum albidum gum compacts}

Chrysophyllum albidum gum (500 mg) were compressed into tablet compacts with pre-determined loads of $28 \mathrm{~N}, 56.5 \mathrm{~N}, 84 \mathrm{~N}, 113 \mathrm{~N}, 141 \mathrm{~N}, 169 \mathrm{~N}$ and $198 \mathrm{~N}$ using a dwell time of 30 seconds on an hydraulic hand press (Model C, Carver Inc., Menomomee Falls, WJ). A 2\% w/w dispersion of magnesium stearate in $96 \%$ ethanol was used to lubricate the die (12.5 $\mathrm{mm}$ in diameter) and the flat faced punches prior to each compression. On ejection, the tablets were stored for $24 \mathrm{hrs}$ over silica gel to allow for hardening and elastic recovery. The 
dimensions and weights were determined within $0.01 \mathrm{~mm}$ and $\pm 1 \mathrm{mg}$ respectively and their relative densities (D) were obtained using Equation 5.

$$
D=W / v t \times P s
$$

where $\mathrm{W}$ is the weight of the tablet $(\mathrm{g})$, vt is the volume of the tablets $\left(\mathrm{cm}^{3}\right)$ and Ps is the solid material particle density $\left(\mathrm{g} / \mathrm{cm}^{3}\right)$. The data obtained were used for the Heckel and Kawakita plots.

\subsection{Compaction data analysis}

\subsubsection{Heckel plot.}

The compressional behavior was analyzed using the Heckel equation [22]:

$$
\operatorname{Ln} \frac{1}{1-D}=K P+A
$$

A plot of Ln (1/1 - D) versus the compression pressure, $\mathrm{P}$ was made. The values of slope, $\mathrm{K}$ for the straight line portion which is the inverse of the mean yield pressure $\mathrm{P}_{\mathrm{y}}$ of the material, $\mathrm{A}$ (the intercept) were obtained from the plots. From the intercept, the relative density $\mathrm{D}_{\mathrm{A}}$ was calculated using Equation 7 :

$$
D_{A}=1-e^{A}
$$

$\mathrm{D}_{0}$, the relative density of the powder bed at zero pressure is the initial rearrangement phase as a result of die filling. The relative density $D_{B}$ which describes the phase of rearrangement during the initial stages of compression was obtained from the difference between $\mathrm{D}_{\mathrm{A}}$ and $\mathrm{D}_{0}$

$$
D_{B}=D_{A}-D_{O}
$$

\subsubsection{Kawakita plot}

The kawakita equation [23] relates the degree of volume reduction, $\mathrm{C}$ with applied pressure $(\mathrm{P})$

$$
P / C=P / a+1 / a b
$$

The constant a (obtained from the slope) is equal to the minimum porosity of the powder bed prior to compression while $b$ is related to the plasticity of the material. Values of $D_{I}(1-a)$ which measures the packed initial relative density of tablets with the application of little pressure were obtained. The reciprocal of $b$ gives $P_{k}$, which is the pressure required to reduce the powder bed by $50 \%$ [24]

\subsection{Preparation of tablets}

Batches $(500 \mathrm{mg}$ ) of metformin formulation containing $2.5 \%, 5 \%$ and $7.5 \%$ of the native and crosslinked Chrysophyllum albidum gum were compressed for 30 seconds into tablets at 1.0 tonne using the direct compression method (Table 5). Prior to compression, the die and punches were lubricated with a $2 \%$ magnesium stearate solution in $96 \%$ alcohol and after ejection, the tablets were stored over silica gel for $24 \mathrm{hrs}$ to allow for elastic recovery.

Table 5. Formulation table of metformin tablet ( 500mg).

\begin{tabular}{llllllll}
\hline $\begin{array}{l}\text { Ingredients } \\
(\% \mathrm{w} / \mathrm{w})\end{array}$ & $\mathrm{A}$ & $\mathrm{B}$ & $\mathrm{C}$ & $\mathrm{D}$ & $\mathrm{E}$ & $\mathrm{F}$ & $\mathrm{G}$ \\
\hline Metformin & 50.0 & 50.0 & 50.0 & 50.0 & 50.0 & 50.0 & 50.0 \\
CCAG & - & 2.5 & 5.0 & 7.5 & - & - & - \\
MCC & 2.5 & 2.5 & 2.5 & 2.5 & 2.5 & 2.5 & 2.5 \\
HPMC & 7.5 & 7.5 & 7.5 & 7.5 & 7.5 & 7.5 & 7.5 \\
NCAG & - & - & - & - & 2.5 & 5.0 & 7.5 \\
Lactose & 40.0 & 37.5 & 35.0 & 32.5 & 37.5 & 35.0 & 32.5 \\
\hline
\end{tabular}




\subsection{Evaluation of tablet strength}

The load required to diametrically break each of the 10 tablets was determined using a Monsanto hardness tester (Copley Scientific Limited, Nottingham, UK), whereas the mean friability of 20 tablets was determined using a friabilator (Shivani Scientific Ind., Mumbai, India) operated at $25 \mathrm{rpm}$ for $4 \mathrm{~min}$.

\subsection{Determination of tablet disintegration time}

The disintegration time for the tablets was carried out in distilled water at $37^{\circ} \mathrm{C}$ using a disintegration test apparatus (Georgeon, Mumbai) and the time it took each tablet to disintegrate and go through the wire mesh was noted. The results are given as mean of five determinations.

\subsection{Determination of dissolution rate of tablets}

Dissolution test for the tablets was carried out using the Veego digital dissolution test apparatus (Veego, India). The dissolution medium used was $900 \mathrm{mls}$ phosphate buffer solution ( $\mathrm{pH}$ 6.8) maintained at $37 \pm 0.5^{\circ} \mathrm{C}$ and the rotating speed was $100 \mathrm{rpm}$. A $5 \mathrm{ml}$ samples were withdrawn at 5, 10, 15, 30, 45 and 60 minutes and replaced with the same volume of fresh medium maintained at the same temperature. The samples withdrawn were filtered through Whatman filter paper and the absorbance of the samples was measured on the spectrophotometer at a wavelength of $233 \mathrm{~nm}$. Determinations were made in triplicate.

Acknowledgements: Authors are grateful to Mr A.A Wahab of NAERL, Ahmadu Bello University for facilitating the analysis of the samples.

Author contributions: Concept - L.G.B., K.E.A.; Design - L.G.B, K.E.A.; Supervision - L.G.B.; Materials - L.G.B; Data Collection and/or Processing - L.G.B., K.E.A.; Analysis and/or Interpretation - L.G.B., K.E.A.; Literature Search L.G.B., K.E.A.; Writing - L.G.B., K.E.A.; Critical Reviews - L.G.B., K.E.A.

Conflict of interest statement: The authors declared no conflict of interest.

\section{REFERENCES}

[1] Adeyanju O, Ewaoche EA, Plavec J. Effect of chemical modification by oxidation on the physicochemical properties of Sweitenia mycrophylla gum. A potential excipient. J Pharm Appl Chem. 2017; 3 (3): 189-194. [CrossRef]

[2] Oladebeye AO, Oshodi AA, Oladebeye AA, Amoo IA. Pasting properties of heat-moisture treated starch of white and yellow yam (Dioscorea specie) cultivars. Nat Sci. 2011; 9 (1): 29-33. [CrossRef]

[3] Lawal OS, Lechner MD, Hartmann B, Kulicke WM. Carboxymethyl cocoyam starch: synthesis characterization and influence of reaction parameters. Starch/Stärke. 2007; 59:224-233. [CrossRef]

[4] Okunlola A, Akingbala O. Characterization and evaluation of acid-modified starch of Dioscorea oppositifolia (Chinese yam) as a binder in chloroquine phosphate tablets. Brazilian J Pharm Sci. 2013; 49(4):699-708. [CrossRef]

[5] Sacco P, Paoletti S, Cok M, Asaro F, Abrami M, Grassi M, Donati I. Insight into the ionotropic gelation of chitosan using tripolyphosphate and pyrophosphate as cross-linkers. Int J Biol Macromol. 2016; 92:476-483. [CrossRef]

[6] Abdulsamad A, Oyi AR, Isah AB, Odidi I. Drug release modification by using citric acid and glycerol cross-linked derivatives of cashew (Anacardium occidentale L.) gum. J Adv Med Pharm Sci. 2005; 3(2): 77-90. [CrossRef]

[7] Ogaji IJ, Nep EI, Audu-Peter JD. Advances in natural polymers as pharmaceutical excipients. Pharm Anal Acta. 2012; 3(1):1- 16. [CrossRef]

[8] Nep EI, Conway BR. Characterisation of grewia gum, a potential pharmaceutical excipient. J Excipients Food Chem. 2010; 1(1): 30-40.

[9] Amusa NA, Ashaye OA, Oladapo MO. Biodeterioration of African star apple (Chrysophylum albidum) in storage and the effect on its food value. Afr J Biotechnol. 2003; 2(3):56-59. [CrossRef]

[10] Ajala TO, Olufunke D, Ajani A, Ihuoma-Chidi C, Odeku OA. Chrysophyllum albidum mucilage as a binding agent in paracetamol tablet formulations. J Pharm Investig. 2016; 46 (6): 565-573. [CrossRef]

[11] Bakre LG, Osideko AO, Bamiro OA. Isolation and characterization of gum from Chrysophyllum albidum fruits as pharmaceutical excipient. J Pharm Biores. 2017; 14(1): 22-30. [CrossRef]

[12] Ologunagba MO, Azubuike CP, Sadiku OR, Silva BO. Evaluation of the binding potential of Chrysophyllum albidum seed gum in Paracetamol tablet formulation. Trop J Nat Prod Res. 2018; 2(3):136-139. [CrossRef] 
[13] Bakre LG, Osunsanya OY, Bamiro OA. The effect of polymer blends on the formulation of sustained release Ciprofloxacin matrix tablets. Nig J Pharm Res. 2018; 14 (1) 35-42.

[14] Polk A, Amsden B, De Yao D, Peng T, Goosen MF. Controlled release of albumin from chitosan-alginate microcapsules. J Pharm Sci. 1994; 83: 178-185. [CrossRef]

[15] Russel J, Lantz J, Pharmaceutical Dosage Forms, third ed., Marcel Dekker Inc., New York, USA, 2005.

[16] Ohwoavworhua FO, Adelakun TA. Some physical characteristics of microcrystalline cellulose obtained from raw cotton of Conchlospermum planchonii. Trop J Pharm Res. 2005; 4 (2): 501-507. [CrossRef]

[17] Goycoolea FM, Calderon de la Barca AM, Balderrama JR, Valenzuela JR. Immunological and functional properties of exudates gum from north western mexican mesquite (Prosopis spp.) in comparison with gum arabic. Int J Biol Macromol. 1997; 21:29-36. [CrossRef]

[18] Bamiro OA, Bakre LG, Faleye Y. Morphology, functional and pasting properties of ginger starches prepared by four different drying methods. British J Pharm Res. 2014; 4: 1439-1450. [CrossRef]

[19] Mbah CC, Ogah JA, Builders PF, Kunle OO. Some physicochemical properties of crosslinked acacia gum. Afr J Pharm Res Dev. 2012; 4 (1): 19-24.

[20] British Standard 1469. British Standard Institution: London, 1970.

[21] United States Pharmacopoeia and National Formulary. United States Pharmacopoeia XXIII: Rockville U.S.P Convention Inc, 2007.

[22] Heckel RW. Density-pressure relationship in powder compaction. Trans Metall, AIME 1961; 222: 671-675.

[23] Kawakita K, Ludde KH. Some considerations on powder compression equations. Powder Technol. 1970/71; 4: 6168. [CrossRef]

[24] Shivanand P, Sprokel OL. Compaction behaviour of cellulose polymers. Powder Technol. 1992; 68: 177-184. [CrossRef] 